\title{
Fetal Brain Transplantation in Kainic Acid Lesioned Caudate Nucleus of Adult Rats
}

\author{
P.N. Tandon ${ }^{2}$, V. Mohan Kumar ${ }^{1}$, Suneeta Verma ${ }^{1}$, Gomathi Gopinath ${ }^{3}$ \\ and Ashok Kumar Shetty ${ }^{3}$ \\ Department of Physiology ${ }^{1}$, Neurosurgery ${ }^{2}$, Anatomy $^{3}$ and National Facility \\ for Neural Transplant, All India Institute of Medical Sciences, \\ New Delhi, 110029, India
}

\section{SUMMARY}

This study confirmed that bilateral kainic acid (KA) injection at the caudate produces aphagia and adipsia in rats. The reduction in food and water intake was fatal after a higher dosage of the drug. To test the effect of transplantation on the mortality rate, KA was first injected in the left caudate, in one set of rats. After a gap of three days, fetal striatal tissue was unilaterally transplanted at this lesioned site, along with a second injection of $\mathrm{KA}$ in the right caudate. Successful transplantation, as ascertained morphologically, did not significantly alter the mortality rate. The morphometric study revealed that the neurons of the transplant were larger in size, and their numerical density lower than those of the caudate of normal rats. Only very few neurons of the transplant developed functional connectivity with the host, as demonstrated by electrophysiological studies.

\section{KEY WORDS}

striatum, kainic acid, neural transplantation, caudate, food intake, water intake, electrophysiology, morphometry

Reprint address:

V. Mohan Kumar

Dept. Physiology

All India Institute of Medical Sciences

Ansari Nagar

New Delhi 110029, India

\section{INTRODUCTION}

Bilateral KA lesions of the striatum in rats produce severe aphagia and adipsia, ultimately causing death /18/. Tulipan et al. /21,22/ reported that neonatal striatal tissue transplants protected the lesioned animals from the syndrome of aphagia and adipsia, but a recent report showed that animals which received neonatal striatal transplants had increased aphagia and adipsia as compared to the controls $/ 15 /$. According to Tulipan et al. /21/, the life-saving effect of the transplant was due to graft survival. However, the post-mortem examination of the brains of these rats did not show any surviving transplants /21/. The optimal age of the donor caudate tissue, which shows the maximal survival rate after transplantation, is $15-17$ days of gestation $/ 16 /$.

In the present study, caudate nuclei of rats were lesioned by local injection of KA. Fetal striatal tissue of the optimal age was transplanted within the lesioned caudate of one set of animals. The extent of destruction produced in the caudate nucleus by $\mathrm{KA}$ was ascertained morphologically. Survival of the transplant was confirmed on post-mortem examination. In addition, the size and density of the neurons in the transplant were studied and compared with those in normal animals. The changes in food and water intake in the transplanted animals were compared with those of lesioned rats without a transplant. The survival rates of rats with $\mathrm{KA}$ lesion alone and those with transplantation (in addition to the lesions) were noted for comparison with the 
earlier reports in the literature. The spontaneous activity of neurons in the transplant was studied electrophysiologically. The changes in the firing rate of these neurons in response to the stimulation of the host substantia nigra (SN) were also investigated to ascertain whether the beneficial effect of the transplant, in terms of survival of the host, was dependent upon the establishment of connectivity.

\section{METHODS}

Experiments were conducted on adult male Wistar rats weighing 150 to $250 \mathrm{~g}$. The animals were housed in a room maintained at $26 \pm 2^{\circ} \mathrm{C}$ with constant light from 05.00 to $19.00 \mathrm{~h}$. Food and water were given ad libitum. The basal food and water intake were measured daily (between 9.00 and $10.00 \mathrm{~h}$ ) for seven days $/ 2 /$. Fifty of those animals which showed regular food and water intake were selected for this study. The food and water intake were continuously monitored for 15 more days after the first operative procedure. In addition, six normal rats were used for morphometric measurements of neuronal size and density for comparison with the experimental group.

The rats were divided into two groups. One group (controls) (22 rats) received bilateral injections of $\mathrm{KA}$ at the caudate, and the second experimental group (28 rats) received unilateral striatal transplants, and bilateral $\mathrm{KA}$ injections. These rats were anaesthetised with ketamine hydrochloride (Parke Davis Limited, India) at a dosage of $30 \mathrm{mg} / \mathrm{kg}$ b.wt. i.p., for lesion of the caudate nucleus. Kainic acid (Sigma, USA), neutralised with $\mathrm{NaOH}$, was injected stereotaxically in the caudate nucleus (A 7.8, L 3.0, H +1.5 , as per atlas of De Groot /7/) on the left side. Three days later an identical amount of $\mathrm{KA}$ was injected on the right side. In the second experimental group, during the second operation, fetal striatal tissue was injected on the left side, i.e., the side which had the kainic acid lesion three days earlier. Both groups were further divided into two subgroups on the basis of the amount $(2 \mu \mathrm{g}$ or $3.5 \mu \mathrm{g})$ of $\mathrm{KA}$ injected at the caudate (Table 1). The volume of fluid injected was $1 \mu \mathrm{l}$, and it was administered over a period of two minutes. The injecting cannula was left in place for an additional two minutes. The weights of animals of different subgroups were not significantly different when compared by Student's t-test.

The tissues for transplantation were taken from foetuses (of 15-17 days gestation) from anaesthetised $(30 \mathrm{mg} / \mathrm{kg}$ ketamine) pregnant rats. Foetuses were removed (one at a time) after laparotomy. The brain was rapidly dissected out and was placed in Ringer's lactate solution. The meninges were carefully removed and the striatal ridge dissected. Approximately $10 \mu \mathrm{l}$ of foetal striatum, along with some sterile saline, was taken up in a glass capillary needle (i.d. $0.6 \mathrm{~mm}$; o.d. $0.8 \mathrm{~mm}$ ), and $4 \mu \mathrm{l}$ was stereotaxically injected (within 10 minutes of dissection) into the lesioned caudate on the left side. All the animals were given an intraperitoneal injection of $2 \mathrm{ml}$ of normal saline with $5 \%$ glucose on the day following the surgery.

The pre-injection food and water intake (at different days) of all the four groups were analysed by using two-way analysis of variance. The food and water intakes of the transplant groups were compared with those of the group which had received an identical dose of KA injections alone by using Wilcoxon's rank sum test. Similarly, the survival rates of transplantation groups of animals were compared with the non-transplanted animals by applying $\chi^{2}$-test with correction factors.

Three to seven months after the transplantation, all the surviving rats were again anaesthetised with urethane ( $1.5 \mathrm{~g} / \mathrm{kg}$ b.wt. i.p.) for electrophysiological recording. A concentric bipolar stainless steel stimulating electrode was lowered to the SN (A 2.6, L 2, H-2.5). Glass micropipettes, filled with $2 \%$ pontamine skyblue dissolved in $0.5 \mathrm{M}$ sodium acetate solution, were guided towards the transplant in the caudate, with the help of a hydraulic microdrive (Narishige Scientific Instruments Laboratories, Japan). Extracellular unit activity picked up by the micropipettes was fed to a P17 unity gain, high input impedance probe (Grass Co., USA) and the signal was amplified 1000 times by passing it through a preamplifier (Tektronix, USA). The amplified signal was fed to a spike analyser (Mentor, USA). The spike analyser was 
TABLE 1

The effect of fetal striatal transplantation on the mortality of rats with kainic acid lesion of the caudate

\begin{tabular}{cccccccc}
\hline & \multicolumn{3}{c}{ Kainic Acid } & & & \multicolumn{2}{c}{ Kainic Acid + Transplant } \\
\cline { 2 - 4 } \cline { 6 - 7 } & Studied & Died & Survived & & Studied & Died & Survived \\
\hline $\begin{array}{c}\text { Low dose } \\
(2 \mu \mathrm{g})\end{array}$ & 7 & 1 & 6 & 11 & 1 & 10 \\
$\begin{array}{c}\text { High dose } \\
(3.5 \mu \mathrm{g})\end{array}$ & 15 & 10 & 5 & & 17 & 10 & 7 \\
\hline
\end{tabular}

set to deliver square wave pulses with each spike falling within the set window level. The single cell activity and window discriminator levels were monitored on a storage oscilloscope. Viewing the response on an oscilloscope was extremely important for checking that the spikes did not change their amplitude and the artifacts did not fall within the window level. The window discriminator output was recorded on one of the channels of the polygraph. The normal firing rate of the unit was recorded about five min before the effect of the stimulation of $\mathrm{SN}$ was studied. The interspike intervals of prestimulatory records were measured to plot their distribution pattern. Frequency of occurrence of various intervals was plotted. The plotted histograms were visually classified as Poisson and Gaussian types.

The effect of stimulation of the $\mathrm{SN}$, with square wave pulses (of $0.3 \mathrm{msec}$ duration, $80-600$ $\mu \mathrm{A}$ current, and $100 \mathrm{~Hz}$ frequency) for $5-10 \mathrm{sec}$, on caudate unit activity was studied. The stimulus effects on each unit were studied thrice. The firing rate of caudate units (per sec) over 5 sec periods prior to stimulation, during stimulation, and for $3 \mathrm{sec}$ after stimulus trains, were calculated for statistical analysis. The stimulatory and post-stimulatory rates were compared with the pre-stimulatory rate using Wilcoxon's rank test at the 5\% significance level. At the end of the recording session, the last point of recording was stained by ejecting pontamine skyblue (Fig. 1A).

The rats were sacrificed at the end of the experiment and the brains perfused with $10 \%$ buffered formalin (formalin diluted in phosphate buffer). Seven $\mu \mathrm{m}$ thick paraffin sections of brain, cut by microtome, were stained with cresyl violet for verification of the lesion and the transplant. The extent of lesion produced by KA on both sides of the brain was assessed by light microscopy. The histological changes in the caudate in transplanted and non-transplanted lesioned rats were compared. Six normal rats were also sacrificed, and their brains were processed, for comparison of morphometric measurements of the host caudate and transplanted cells. The numerical density of neurons per unit volume, the area, perimeter, maximum diameter and minimum diameter of the cells in three, four, five, six and seven month old transplants, kainic acid lesioned caudates and control caudates were carried out using an IBAS image analyser (Kontron, FRG). The mean values of area, perimeter and diameter of neurons were determined from ten frames in each animal. Numerical density was calculated using a stereology programme. All the values were statistically analysed using Student's t-test (two-tailed). Similarly, values from the transplant and kainic acid lesion sites were compared with the control using the same test.

\section{RESULTS}

The survival rate of the rats which received bilateral injections of $2 \mu \mathrm{g}$ of KA in the caudate was $86 \%$. Survival was $91 \%$ for the rats which received $2 \mu \mathrm{g}$ of $\mathrm{KA}$ and a foetal striatal 

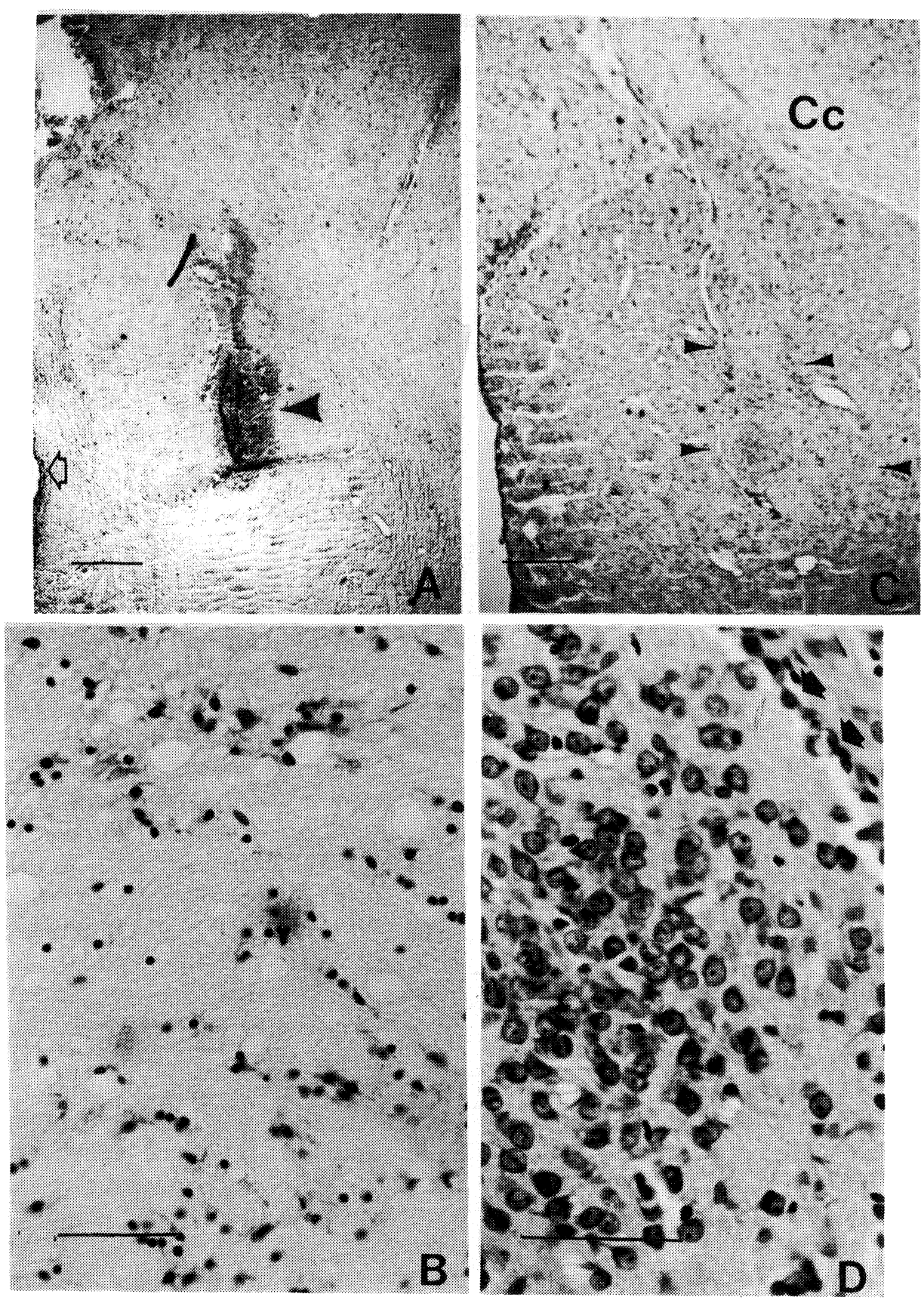

Fig. 1: A. Cresyl violet-stained section showing pontamine stain (arrow head) in the caudate transplant indicating the recording electrode site. Open arrow - Ventricle; calibration bar $300 \mu$.

B. Higher magnification of the kainic acid lesioned caudate. Note the absence of neurons. Calibration bar $100 \mu$.

C. Photomicrograph of cresyl violet-stained sections showing transplant (indicated by arrows) in the caudate nucleus. Cc - corpus collosum; calibration bar $200 \mu$.

D. Higher magnification of a region of transplant to show surviving neurons. Arrows show interface between transplant and host caudate. Calibration bar $50 \mu$. 
transplant. Sixty six percent of the rats that received $3.5 \mu \mathrm{g}$ of $\mathrm{KA}$ alone developed aphagia and adipsia and died within seven days after the second injection (Table 1). The mortality rate was $59 \%$ among those which received $3.5 \mu \mathrm{g}$ of $\mathrm{KA}$ and the transplant. The mortality (or survival) of animals in transplanted and nontransplanted groups was comparable.

The brains of rats which received KA injections showed variation in the extent of lesion. The lesion extended along the cannula tract causing destruction in some adjoining cortical regions in addition to the caudate nucleus. The lesioned area had, mostly, glial cells (Fig. 1B). The numerical density of neurons on the KA injected site was low (Table 2, Fig. 1B) as compared to the normal caudate. The size of the surviving host caudate neurons was comparable to the normal. Well-formed striatal transplants were found in the rats that received injection of foetal tissue (Figs. 1C, D). The transplants were well delineated and could be clearly distinguished from the host tissue on the basis of cellular organisation. There was no difference in the numerical density and cell size of the transplant in the different rats which had been sacrificed from three to seven months after transplantation (Fig. 2). The average cell size of the neurons in the transplant was larger (Table 2) than the normal caudate neuron.

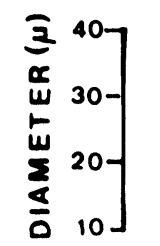

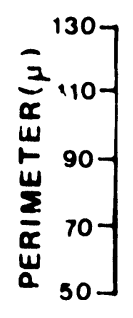<smiles>[3H]C([3H])[CH][CH][CH]</smiles><smiles>CC(C)[C-]C(C)C1CC1</smiles>
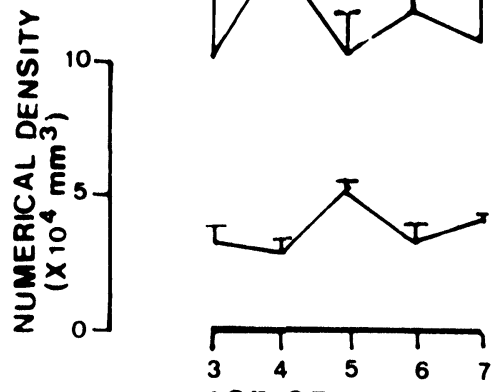

AGE OF TRANSPLANT

(MONTHS)

Fig. 2: The diameter, perimeter, area and numerical density of the cells in three to seven months old transplants are shown. Three animals were sacrificed at each of the time periods indicated in the graph.

\section{TABLE 2}

Density and size of neurons in normal caudate, KA lesioned caudate, and striatal transplant

\begin{tabular}{lccccc}
\hline & $\begin{array}{c}\text { Numerical } \\
\text { Density } \\
\times 10^{4} / \mathrm{mm}^{3}\end{array}$ & Area & Perimeter & Diameter \\
\cline { 3 - 5 } & $5.14 \pm 0.8$ & $227.14 \pm 48.89$ & $60.74 \pm 7.15$ & $19.91 \pm 2.36$ & $15.28 \pm 1.85$ \\
\hline $\begin{array}{l}\text { Normal caudate } \\
\text { (control animals) }\end{array}$ & $3.78 \pm 0.23$ & $292.02 \pm 50.54$ & $68.95 \pm 6.56$ & $23.03 \pm 7.09$ & $16.91 \pm 1.74$ \\
$\begin{array}{l}\text { KA lesioned } \\
\text { caudate }\end{array}$ & $3.68 \pm 0.83$ & $407.78 \pm 99.45$ & $81.78 \pm 10$ & $27.73 \pm 3.27$ & $19.62 \pm 2.38$ \\
$\begin{array}{l}\text { Striatal transplant } \\
\text { in KA lesioned } \\
\text { caudate }\end{array}$ & & & & & Minimum \\
\hline
\end{tabular}


There was no significant variation in the quantity of food and water consumed by the different animals during the pre-injection period. The food and water intake showed a statistically significant fall on the day following the injection of $2 \mu \mathrm{g}$ of KA but it showed significant recovery by the second day after the injection (Fig. 3). The reduction was more marked and prolonged after injection of $3.5 \mu \mathrm{g}$ of KA. Similar changes in food and water intake were produced in transplanted animals also after KA injection.

Spontaneous electrical activity was recorded from 25 units in the transplant. The normal rate of firing of the neurons of the transplant varied from 1.2 to 20.3 spikes per second (mean $4.21 \pm$ 5.29) though the firing rate of most of the neurons ranged between 1.2 and 4.75. The resting firing pattern of $66 \%$ of cells showed a Poisson pattern, whereas $22 \%$ of the cells showed a Gaussian firing pattern. It was not possible to decipher the firing pattern of $12 \%$ of the cells. Of the 25 units studied, only two neurons were influenced by stimulation of $\mathrm{SN}$ of the same side. Of those influenced, one showed inhibition and the other excitation (Fig. 4).

\section{DISCUSSION}

In this study the lethal dose of KA was found to be $3.5 \mu \mathrm{g}$. The survival rate of rats which received a striatal transplant in addition to $\mathrm{KA}$ was not significantly different from those which did not receive a transplant. KA injection at the caudate produced a dose dependent decrease in food and water intake in all animals. Aphagia and adipsia were persistent in all animals which died after KA injection. The changes in food and water intake in the transplant group were not different from those of the non-transplant group.

A well-formed transplant was found in the brains of all the rats which received foetal transplants. The average size of the neurons in the transplant was larger and their density lower than the normal caudate. There were neurons in the transplant which had spontaneous electrical activity. These neurons generally had a Poisson distribution of firing. On stimulation of the SN of the host, two neurons of the transplant showed alteration in their firing rates.
The amount of KA which was required to produce lethal changes was found to be $3.5 \mu \mathrm{g}$, as compared to $2 \mu \mathrm{g}$ reported earlier /21,22/. Variation in the destructive effect of KA is well documented /14/. Extensive damage of the caudate may be responsible for the persistent aphagia, adipsia and death of some of the animals during the first week after injection $/ 18 /$.

In the present study, all the foetal transplants survived, in contrast to earlier reports, where surviving neonatal grafts were not observed on post-mortem examination $/ 21,22 /$. This further confirms the earlier finding that 15-17 day-old foetal striatal tissue has a better survival rate than neonatal tissue /16/. Nash et al. /15/, on the other hand, did find surviving neonatal graft tissue in some rats. The larger size of neurons in the transplant, as compared to the neurons in normal caudate, was difficult to explain. It does not represent an early degenerative change, as similar changes were observed in grafts of all ages. In our earlier study using SN transplants in the striatum, no degenerative change, premature ageing, or diminution in density of surviving neurons was observed for one year after transplantation $/ 11 /$.

The survival rate of animals which had received the transplant was statistically not higher than the ones which had not. Thus the present study does not confirm the earlier report that the transplantation provides protection to the recipient from lethal aphagia and adipsia /21/. Nor does it support the contention of Nash et al. /15/ that the animals which received transplants showed increased aphagia and adipsia. Though striatal transplants have been reported to reverse locomotor and other functional deficits produced by injection of excitotoxic agents $/ 6,12 /$, the present study showed that it does not affect aphagia and adipsia. It may be recalled that adipsia and aphagia produced by dopamine denervation of the caudate-putamen were also unaffected by $\mathrm{SN}$ transplantation $/ 8 /$. Therefore, it appears that the survival of the transplant does not provide any beneficial effect for the changes in food and water intake. It is possible that some humoral factors released by the degenerating graft might have provided some protective effect to the recipient in the study of Tulipan et al. $/ 21 /$. 


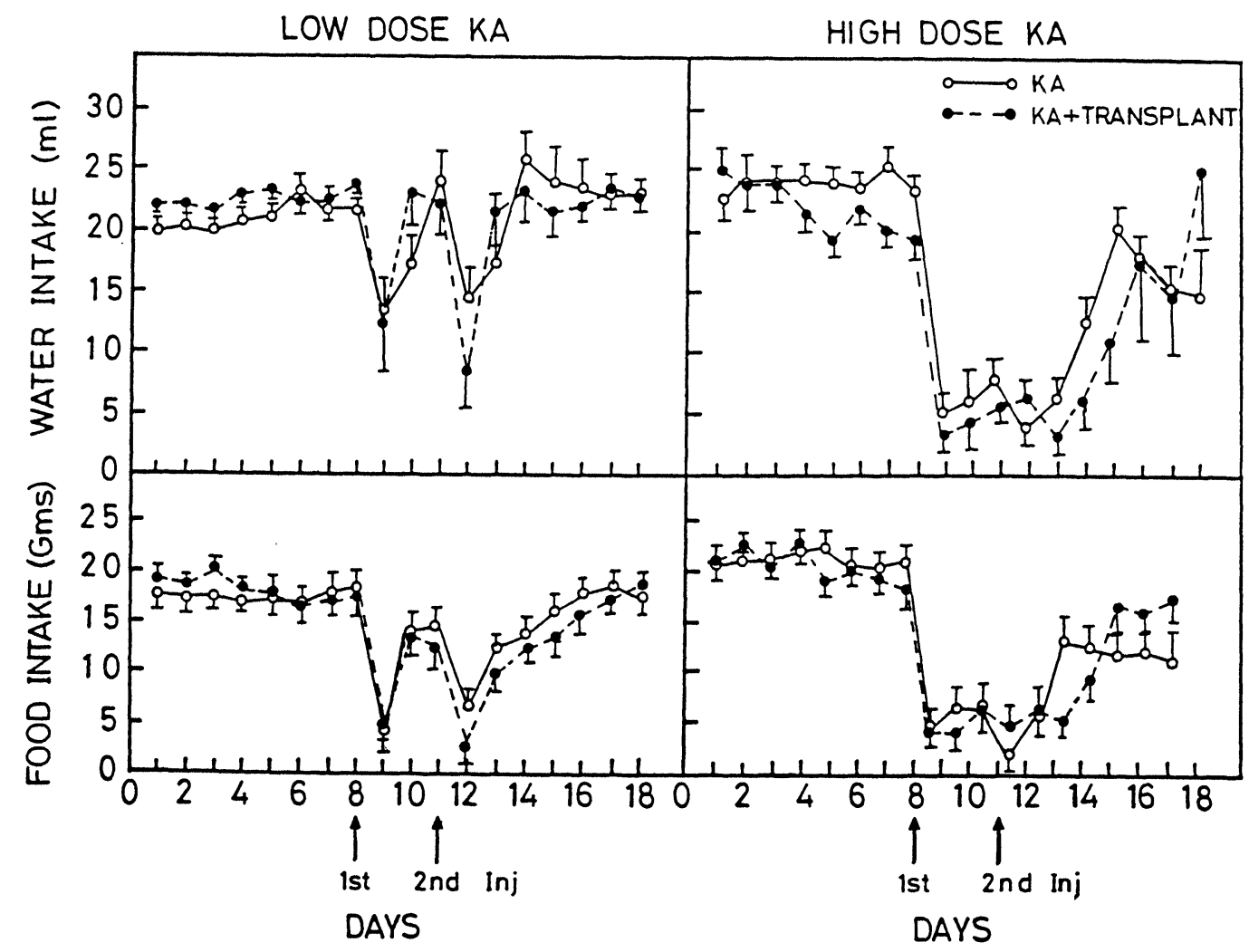

Fig. 3: The means \pm SE of food and water intake of rats after kainic acid lesion and transplant in the caudate nucleus are shown. Aphagia and adipsia produced were short lasting and prolonged after low ( $2 \mu \mathrm{g})$ and high $(3.5 \mu \mathrm{g})$ dose injections of $\mathrm{KA}$, respectively, and they were independent of additional administration of transplant tissue. The reading given after the second high dose injection represents the mean food and water intake $( \pm S E)$ of the surviving rats.

1

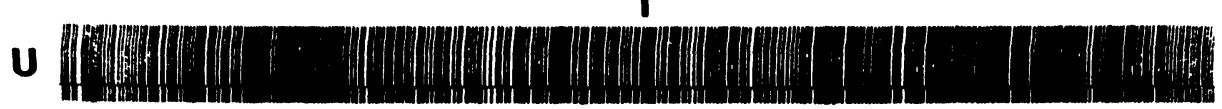

st

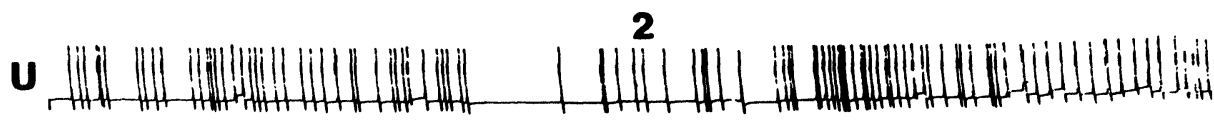

St

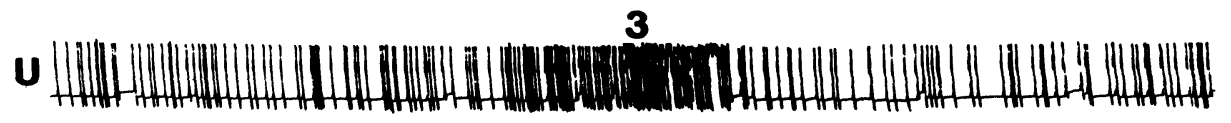

St

TIMER 1/SeC

Fig. 4: The effect of stimulation of SN (600 A) on three units recorded from the transplants. Most of the neurons were unaffected (1) by stimulation, though one was inhibited (2) and another excited (3). $U$ - unit activity (window discriminator output). St - Stimulus. 
There are some differences in the experimental approach of our study as compared to those of Nash et al. /15/ and Tulipan et al. /21,22/. Wistar rats were used in this study, whereas Sprague Dawley and Lewis rats were used in the other two studies, respectively. The weight range of animals of our study was lower than that used by Nash et al. $/ 15 /$, but was nearer to those of Tulipan et al. /21/. Besides these differences, foetal tissue (15-17 days) was transplanted in the present study, whereas neonatal tissue was used in the other two.

The cells of the transplant developed normal spontaneous electrical activity, as is evident from the recording of spontaneous firing from 25 units in this study. Their firing rates were comparable to those found in the striatum of normal urethane anaesthetised rats $/ 19 \%$. The Poissonian distribution of the firing may indicate the development of functional connections by the transplanted neurons $/ 17,24 /$. Striatal transplants were reported to develop afferent and efferent anatomical connections with various regions of the host brain including SN /23/. As stimulation of the host $\mathrm{SN}$, which normally forms an important input to the caudate $/ 1,3,4,5,9,10,12,13 /$, did not affect most of the neurons studied, it is possible to conclude that the major functional connections of the transplant are not from the host. It is possible that the transplanted cells developed connections between themselves. This was observed in our earlier morphological studies $/ 20 \%$. The percentage (9\%) of neurons in the transplant showing response to stimulation of $\mathrm{SN}$ was much lower than that reported (63\%) in normal animals $/ 3-5 /$. Even this small number of neurons, which responded to SN stimulation, forms an important landmark in the understanding of the functional integration of the transplant with the host brain.

\section{ACKNOWLEDGEMENT}

The financial support given by the Department of Science and Technology is gratefully acknowledged.

\section{REFERENCES}

1. Albe-Fessard D, Raieva S, Santiago W. Sur les relations entre substance noire et noyau caude. J Physiol (Paris) 1967; 59: 324-325.

2. Bhanot JL, Chhina GS, Singh B, Sachdeva U, Mohan Kumar V. REM sleep deprivation and food intake. Ind J Physiol Pharmacol 1989; 33: 139-145.

3. Connor JD. Effects of substantia nigra stimulation on firing patterns of caudate neurons. Fed Proc 1968; 27: 755.

4. Connor JD. Caudate unit responses to nigral stimuli: Evidence for a possible nigro-neostriatal pathway. Science 1968; 160: 899-900.

5. Connor JD. Caudate nucleus neurons: Correlation of the effects of substantia nigra stimulation with iontophoretic dopamine. J Physiol 1970; 208: 691-703.

6. Deckel AW, Robinson RG, Coyle JT, Sanberg PR. Reversal of long term locomotor abnormalities in the kainic acid model of Huntington's disease by 18 day fetal striatal implants. Eur J Pharmacol 1983; 93: 287 288.

7. De-Groot J. The rat forebrain in stereotaxic coordinates. Trans R Neth Acad Sci 1959; 52: 1-40.

8. Dunnett SB, Bjorklund A, Schmidt RH, Stenevi U, Iverson SD. Intracerebral grafting of neuronal cell suspension: V. Behavioural recovery in rats with bilateral 6-OHDA lesions following implantation of nigral cell suspensions. Acta Physiol Scand (Suppl) 1983; 522: 39-48.

9. Feltz P, MacKenzie JS. Properties of caudate unitary responses to repetitive nigral stimulation. Brain Res 1969; 13: 612-616.

10. Frigyesi TL, Purpura DP. Electrophysiological analysis of reciprocal caudato-nigral relations. Brain 1967; 6: 440-456.

11. Gopinath G, Shetty AK, Tandon PN. Ageing changes in the transplants of fetal substantia nigra grafted to striatum of adult rat. Neuroscience 1991; 40: 429-443.

12. Isacson O, Brundin PM, Keldy PAT, Gage FH, Bjorklund A. Functional neuronal replacement by grafted striatal neurons in the ibotenic acid lesioned rat striatum. Nature 1984; 311: 458-460.

13. McLennan $\mathrm{H}$, York $\mathrm{DH}$. The action of dopamine on neurons of the caudate nucleus. J Physiol 1967; 189: 393-402.

14. Moore RY. Methods for selective restricted lesion placement in the central nervous system. In: Heimer L, Robards MJ, eds, Neuroanatomical Tract-Tracing Methods. New York: Plenum Press, 1981; 55-89.

15. Nash DR, Kaplan SM, Norman AB, Sanberg PR. An evaluation of the possible protective effects of neonatal striatal transplants against kainic acidinduced lesions. J Neur Transplant Plasticity 1991; 2: 75-79. 
16. Olson L, Bjorklund H, Hoffer BJ. Camera bulbi anterior: New vistas on a classical locus for neural tissue transplantation. In: Sladek JR Jr, Gash DM, Eds, Neural Transplants: Development and Function. New York: Plenum Press 1984; 125-165.

17. Palkovits M, Zaborszky L. Neural Connections of the Hypothalamus. In: Morgane PJ, Panksepp J, eds, Handbook of the Hypothalamus: Anatomy of the Hypothalamus, Vol. 1. New York: Marcel Dekker, 1979; 379-509.

18. Pettibone DJ, Kaufman N, Scally MC, Meyer E, Ulus I, Lytle LD. Striatal non-dopaminergic neurons: Possible involvement in feeding and drinking behaviour. Science 1978; 200: 1175-1177.

19. Richardson TL, Miller JJ, McLennan H. Mechanism of excitation and inhibition in the nigrostriatal system. Brain Res 1977; 127: 219-234.

20. Shetty AK, Banerjee R, Gopinath G, Tandon PN. Fetal nigral grafts in the anterior eye chamber of adult rats: A long term morphological study. Exp Neurol 1991; 111: 106-114.

21. Tulipan N, Huang S, Whetsel WO, Allen GS. Neonatal striatal grafts prevent lethal syndrome produced by bilateral intrastriatal injection of kainic acid. Brain Res 1986; 377: 163-167.

22. Tulipan N, Luo S, Allen GS, Whetsall WO. Striatal grafts provide sustained protection from kainic acid and aminolinic acid-induced damage. Exp Neurol 1988; 102: 325-332.

23. Wictorin K, Simerly RB, Isacson O, Swanson LW, Bjorklund A. Connectivity of striatal grafts implanted into the ibotenic lesioned striatum. III: Efferent projecting graft neurons and their relation to host afferents within the grafts. Neuroscience 1989; 30: 313330.

24. Zelenskaia VS, Gruzdev GM, Nizyaeva EV. Anoeliz Fonovot aktivnosti neironov khvostatogo iadra. Neirofiziologiya 1977; 9: 369-376. 

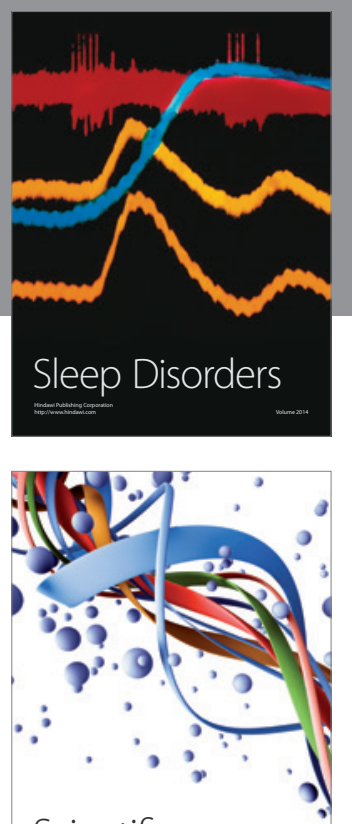

Scientifica
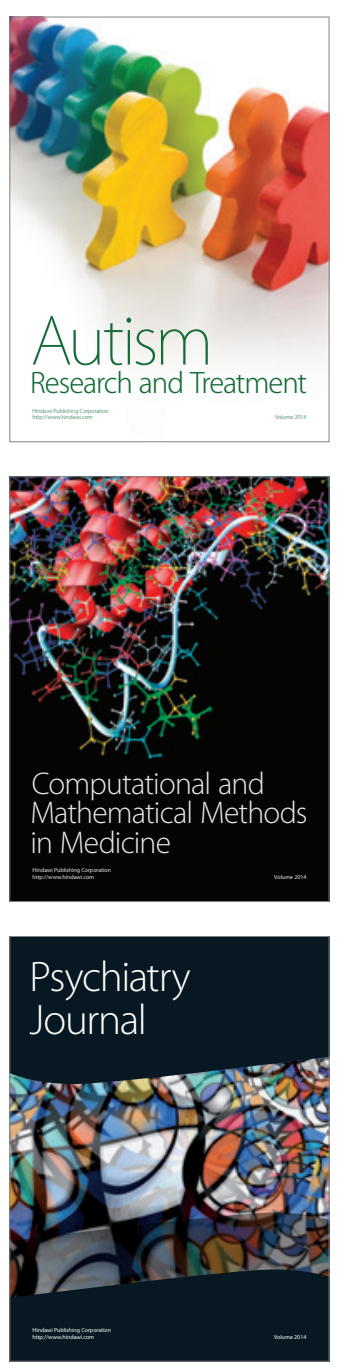
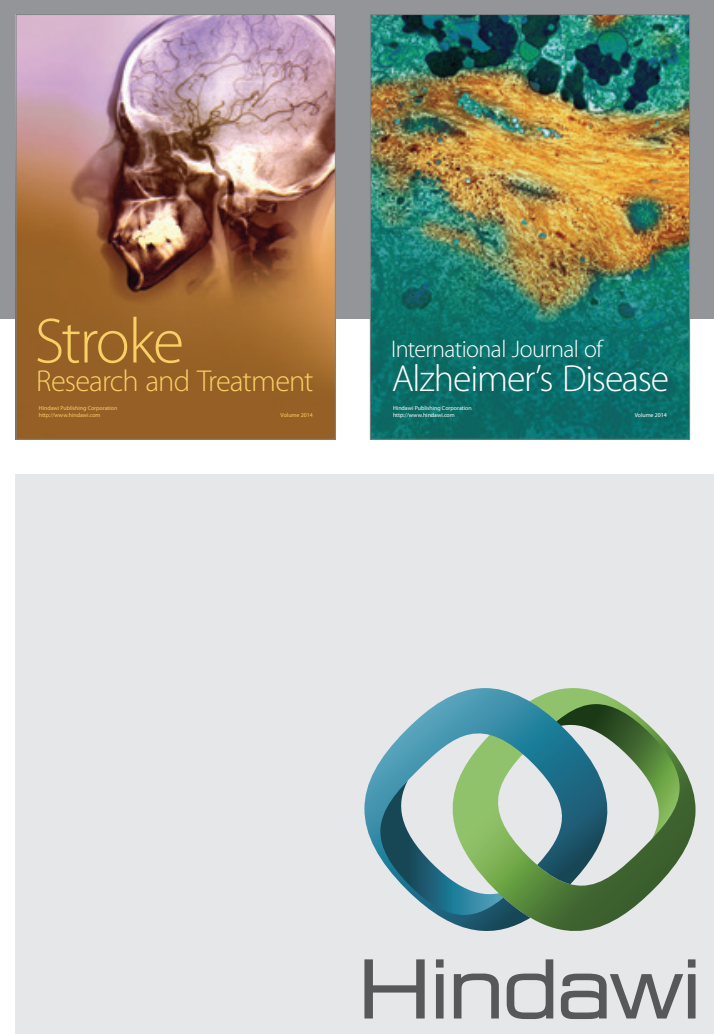

Submit your manuscripts at

http://www.hindawi.com
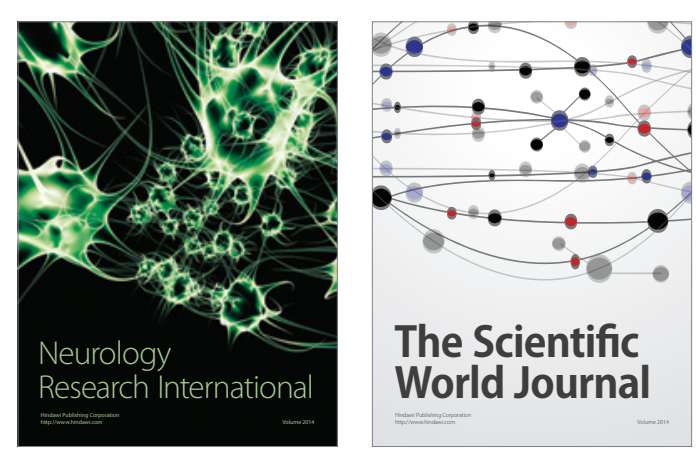

The Scientific World Journal

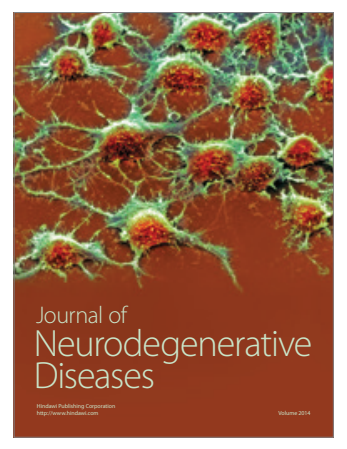

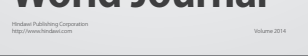

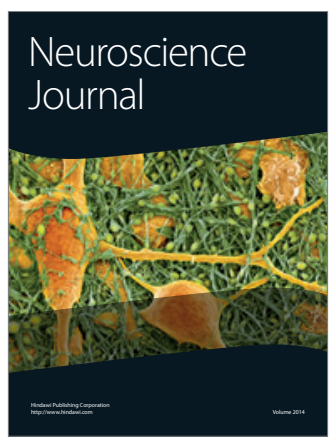

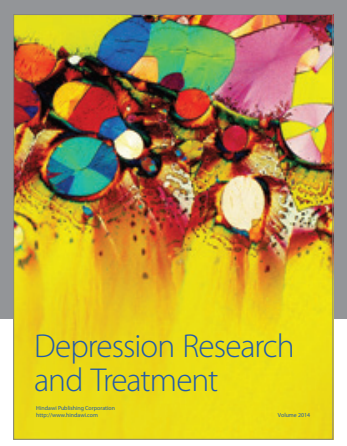
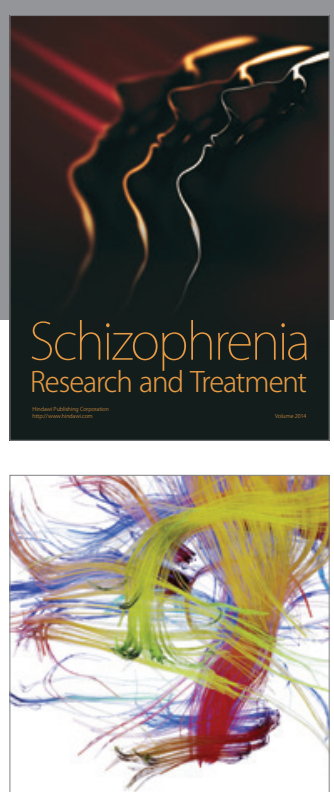

Brain Science

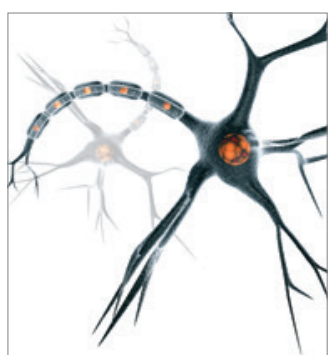

Neural Plasticity
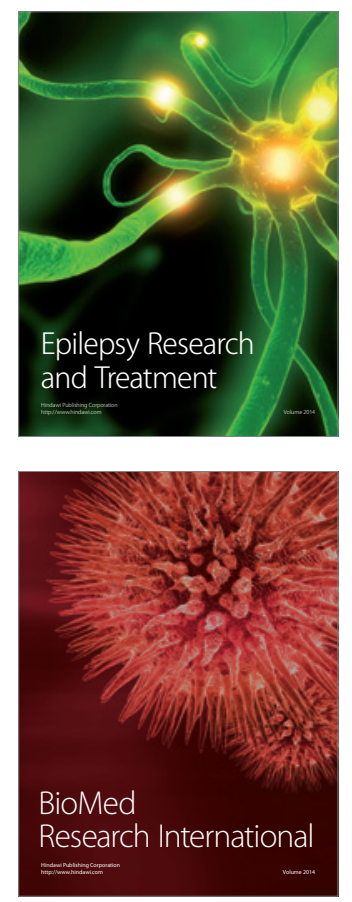

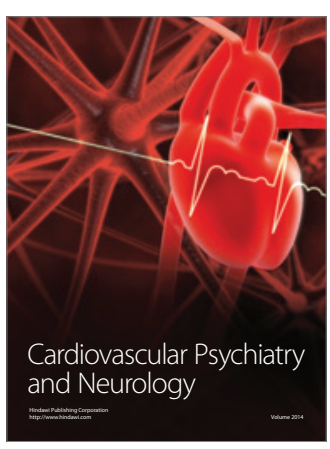

Parkinson's

Disease
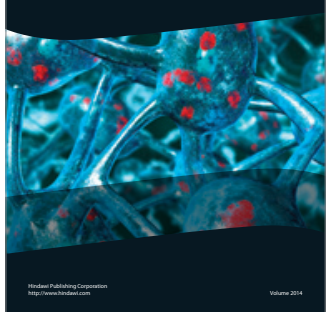